\title{
Potential Factors Associated with Epilepsy among Epileptic Patients Attending Middle Euphrates Neurosciences Center - Al-Najaf City
}

\author{
Sahar Adham Ali ${ }^{1}$, Hayder Ibrahim Ali ${ }^{2}$, Hasan Alwan Baiee ${ }^{3}$ \\ ${ }^{1}$ University of Babylon -College of Nursing, Iraq, ${ }^{2}$ Higher Health Institute AL-Najaf Health Directorate, Iraq, ${ }^{3}$ \\ University of Babylon-College of Nursing, Iraq
}

\begin{abstract}
Objective: To identify the some factors associated with epilepsy. A Case-control study was carried out at Middle Euphrates Neurosciences Center in An-Najaf City- Iraq, the study was conducted from mid of October 2016 until mid of March 2017. Participants recruited in the study were selected as conveniently, (74) of them were already diagnosed by neurologist as epileptics patients and considered as cases, while (140) were non-epileptic from same setting considered as control group. instrument structured for this purpose, data collection was done using pretested questionnaire which consist of two parts, first one included: biographical data (age, gender, marital status, level of education, occupation, and resident). The cases and control groups are age and sex matched. Epileptic patients had a significantly low level of education (Not read and write) $34.4 \%$ as compared to healthy control group $13,3 \%$ this difference is statistically significant $\mathrm{p}<0.05$ the Odds Ratio (OR) was 2.1.,the following possible risk factors were significantly associated with epilepsy in this study; unemployment $\mathrm{OR}=2.7$, positive family history $\mathrm{OR}=1.8$, central nervous system lesions $\mathrm{OR}=4.3$ and natal defects $\mathrm{OR}=8.3$.
\end{abstract}

Keywords: epilepsy, risk factors, Iraq

\section{Introduction}

Epilepsy is a common health problem that effect peoples and it is featuring as a seizure attacks with differences in clinical events, that need to be treated by use of medications ${ }^{6}$.Epilepsy can occur at any age, race, ethnic ${ }^{5}$. More than $10 \%$ of people around the world were effected with single attack of abnormal movement, generally single attack not classified as epilepsy if not affected at least two unprovoked seizures attack separated by 24 hours, but the person at risk for recurrent and appear as epileptic patient ${ }^{8}$. About 724,500 epileptic patients are distributed in Arab countries according to epidemiological review in Arab countries for epilepsy ${ }^{1}$. The risk evolving for epilepsy in life of person along life time is $1.4-3.3 \%{ }^{\mathbf{1 3}}$. Many factors are associated with occurrence of secondary epilepsy or considered as risk factors for it if present in person like family history, any brain lesion (tumor, trauma, and cerebrovascular accident), and central nervous system infection. Otherwise if not associated with any mentioned factor consider primary (unknown cause) epilepsy ${ }^{9}$. People who are affected with epilepsy are interesting to identify the risk factors related to underling health condition 11, 25\%-45\% of epileptic patients, were affected with epilepsy related to many causes such as hereditary, brain structure lesion, or metabolically disturbances cause, while other peoples with epilepsy considered an idiopathic affect ${ }^{4}$. Family history according to antecedent studies consider one of major risk factors affecting young age ${ }^{8}$. It is important to predict the potential risk factor for epilepsy to take preparation of health planning contribution ${ }^{3}$. This study was conducted to identify the risk factors associated with epilepsy.

\section{Methodology}

A Case-control design was carried out at Middle Euphrates Neurosciences Center in An-Najaf City which is the single specialist center established in (2010) to cover the needs of neurological consultations for population in south region of Iraq, the study period from 16 October 2016 until 16 March 2017. Data were 
collected from (214) patients selected as a convenience sampling, (74) of them were already diagnosed with epilepsy considered as cases group, while (140) were non-epileptic from the same setting considered as control group. This data were achieved verbally by direct interview with both who attend as outpatients of the center, structured questioner was constructed for this purpose, the using form consist of two parts, the first one includes: demographical characteristics (age, gender, marital status, level of education, occupation, and residence), while the second part consists of questions about potential risk factors for epilepsy such as family history, history of central nervous system lesion that result from (infection, congenital defect, trauma, tumor, and other defects for CNS), pregnancy and delivery factors, other potential risk factors, and unknown risk factors for epilepsy. Reliability of the questions was (0.68) of the form were calculated after carrying out a pilot study which included (20) participants who excluded from the study sample, the validity of the study tool was done through reviewing by panel of (10) experts. The selection of patients considered the clinical diagnosis of patients and using of chronic disease identification form which used for free medications and the diagnosis confirmed by electroencephalograph (EEG). Statistically analysis was done using Odds Ratio (OR) with measure the risk, OR more than one considered as a positive association.

\section{Results and Discussion}

The current case-control study includes 74(35.2\%) epileptic patients and $140(64.8 \%)$ non-epileptic patients. Table (1) shows differences in distribution of sociodemographic characteristics among case and control group, males 117 (54.7\%) more than females 97 (45.3\%) in all sample. Most of them were married 128 (59.8\%) and $86(40.2 \%)$ were single. $45(21.0 \%)$ were read and write, while $3(1.4 \%)$ had higher academic level of education. The highest 77 (36.0\%) were not working, $136(63.6 \%)$ were living in urban area.

Table (1) Distribution of Socio-demographic characteristics of sample

\begin{tabular}{|c|c|c|c|}
\hline \multirow{2}{*}{\multicolumn{2}{|c|}{ Socio-demographic characteristics }} & \multirow{3}{*}{\begin{tabular}{|l|} 
Cases \\
No. $(\%)$ \\
$40(54 \%)$ \\
\end{tabular}} & \multirow{3}{*}{$\begin{array}{l}\text { Control } \\
\text { No. }(\%) \\
17(12.2 \%)\end{array}$} \\
\hline & & & \\
\hline \multirow{4}{*}{ (Age groups) years } & $(1-18)$ & & \\
\hline & $(19-36)$ & $18(24.3 \%)$ & $60(42.9 \%)$ \\
\hline & $(37-54)$ & $9(12.2 \%)$ & $46(32.8 \%)$ \\
\hline & (55 and more) & $7(9.5 \%)$ & $17(12.1 \%)$ \\
\hline \multirow{2}{*}{ Gender } & Male & $41(55.4 \%)$ & $76(54.3 \%)$ \\
\hline & Female & $33(44.6 \%)$ & $64(45.7 \%)$ \\
\hline \multirow{2}{*}{ Marital status } & Single & $53(71.6 \%)$ & $33(23.6 \%)$ \\
\hline & Married & $21(28.4 \%)$ & 107 (76.4\%) \\
\hline \multirow{5}{*}{ Levels of education } & Not read and write & $24(32.4 \%)$ & $20(14.3 \%)$ \\
\hline & read and write & $14(18.9 \%)$ & $31(22.1 \%)$ \\
\hline & Primary school & $19(25.7 \%)$ & $22(15.7 \%)$ \\
\hline & Secondary school & $14(18.9 \%)$ & $30(21.4 \%)$ \\
\hline & Academic holder & $3(4.1 \%)$ & 37 (26.4\%) \\
\hline \multirow{4}{*}{ Occupation } & Not working & $47(63.5 \%)$ & $30(21.4 \%)$ \\
\hline & Free working & $10(13.5 \%)$ & $25(17.9 \%)$ \\
\hline & Office holder & $15(20.3 \%)$ & $40(28.6 \%)$ \\
\hline & House wife & $2(2.7 \%)$ & $45(32.1 \%)$ \\
\hline \multirow{2}{*}{ Place of Residence } & Urban & $40(54.1 \%)$ & $96(68.6 \%)$ \\
\hline & rural & 34 (45.9\%) & $44(31.4 \%)$ \\
\hline
\end{tabular}

Table (1) shows that (1-18) years were the highest age group in case, while in control group the age group (1936) years was the highest. 
In consideration of gender in case group the male were 41 (55.4\%) more than female 33 (44.6\%), like that in control group the male group was $76(54.3 \%)$ more than female $64(45.7 \%)$.

Regarding to marital status 53 (71.6\%) were single case group, while in control group 107 (76.4\%) were married.
The highest percentage were not read and write related to level of education in case group was 24 (32.4\%), while in control group the highest were 34 (24.3\%) for Academic holder.

Regarding to place of residence most of cases 40 $(54.1 \%)$ were living in urban area in case group and control group 96 (68.6\%).

Table (2) Distribution of the Associated Risk Factors Among the Study Group

\begin{tabular}{|c|c|c|c|c|}
\hline \multirow{2}{*}{ Risk factors } & \multirow{2}{*}{ Exposed } & Cases & Control & \multirow{2}{*}{ OR } \\
\hline & & F (\%) & F (\%) & \\
\hline \multirow{2}{*}{ Family history } & Not Exposed & $39(52.7 \%)$ & $94(67.1 \%)$ & \multirow{2}{*}{1.83} \\
\hline & Exposed & $35(47.3 \%)$ & $46(32.9 \%)$ & \\
\hline \multirow{2}{*}{ CNS lesion } & Not Exposed & $34(45.9 \%)$ & $110(78.6 \%)$ & \multirow{2}{*}{4.31} \\
\hline & Exposed & $40(54.1 \%)$ & $30(21.4 \%)$ & \\
\hline \multirow{2}{*}{ Antenatal def. } & Not Exposed & $45(60.8 \%)$ & $130(92.9 \%)$ & \multirow{2}{*}{8.37} \\
\hline & Exposed & $29(39.2 \%)$ & $10(7.1 \%)$ & \\
\hline \multirow[b]{2}{*}{ Others diseases } & Not Exposed & $70(94.6 \%)$ & $135(96.4 \%)$ & \multirow{2}{*}{1.54} \\
\hline & Exposed & $4(5.4 \%)$ & $5(3.6 \%)$ & \\
\hline
\end{tabular}

\section{CI $($ confidence interval $)=95 \%, \mathrm{OR}=$ Odds Ratio}

Table (2) presented the distribution of OR (1.83) for (74) epileptic patients in case group $35(47.3 \%)$ patient exposed with family history and $39(52.7 \%)$ are not exposed, in control group 46 (32.9\%) exposed and $94(67.1 \%)$ are not exposed, OR (4.31) for 40 (54.1\%) exposed to CNS lesion and $34(45.9 \%)$ are not exposed in case group, while in control group 30 (21.4\%) exposed to same lesion and $110(78.6 \%)$ are not exposed, for $29(39.2 \%)$ exposed and $45(60.8 \%)$ not exposed to natal defects in case group, and $10(7.1 \%)$ exposed and $130(92.9 \%)$ not exposed the OR was (8.37). With history of other chronic disease potential risk factor the OR (1.54) for 4 (5.4\%) exposed in case group and 70 (94.6\%) are not exposed in same group, but in control group the exposed to these factors were $5(3.6 \%)$ and not exposed were 135 (96.4\%). The current study curried out to identify the risk factors for epilepsy in 74 participants who classified as disease compared with 150 participants no disease as control group. This study explain the association between different factors studies such as family history, brain lesion, natal and postnatal defects, the Odds ratio in all these exposure are more than 1.5 this means the associations are positive and the factors studies are related to the development of this disease. Family history is one of the major risk factors for epilepsy as that found by ${ }^{\mathbf{1 0}}$. in their study in Iran at 2007, in current study family history had positive affect for occurrence of epilepsy. Central nervous system lesion included infection, congenital defect, trauma, tumor and other defects are positively associated with the study in occurrence of epilepsy in population, this finding is similar to Bhalla D. and Lotfalinezhad E. in their study at 2016 when presented that stroke is a significant risk factor for epilepsy. Wang $H$. et. al. in their study of Influential factors of epilepsy following aneurismal subarachnoid hemorrhage found that many aneurismal subarachnoid hemorrhage cases result in epilepsy that confirm the reality of brain lesion effect in occurrence of epilepsy. Prenatal, antenatal and post-natal defect history detect in this study have positive effects this defect distributed among (asphyxia, low weight, premature, trauma during delivery, jaundice, febrile seizure) this 
finding agree with ${ }^{7}$ who find in their study of Epileptic Encephalopathy in Children as Risk Factors for Brain Damage effect of prenatal and perinatal brain defect history on occurrence of epilepsy of many children. In view of point family history considered a risk factor in occurrence of epilepsy together with exposure to trauma and exposure to congenital anomalies and antenatal, post natal.

\section{Conclusion}

There are a strong association between epilepsy and family history, nervous system lesion, natal defect and other diseases.

\section{Conclusion}

Financial Disclosure: There is no financial disclosure.

Conflict of Interest: None to declare.

Ethical Clearance: All experimental protocols were approved under the University of Babylon -College of Nursing, Iraq and all experiments were carried out in accordance with approved guidelines.

\section{References}

1- Benamer HTS, Grosset DG . A systematic review of the epidemiology of epilepsy in Arab countries, Epilepsia, 2009; 50(10):2301.

2- Bhalla D, Lotfalinezhad E. A Short Perspective on the Risk Profile of Epilepsy in Iran. M J Neuro 2016;1(1): 1-3.

3- Canpolat M, Kumandas S, Poyrazoglu H G, Gumus H , Elmali F , Per H . Prevalence and risk factors of epilepsy among school children in Kayseri City Center, an urban area in Central Anatolia, Turkey, Elsevier, 2014; 23 (2014) 708-716.

4- Chou I, Wang C, Lin W, Tsail F, Lin C, Kao $\mathrm{C}$, Risk of epilepsy in type 1 diabetes mellitus: a population-based cohort study, Springer-Verlag Berlin Heidelberg 2016; 1-3.

5- Escoffery C, McGee RE, Bamps Y, Helmers SL. Differences in Epilepsy Self-Management Behaviors among Young and Older Adults. Austin J Neurol Disord Epilepsy. 2016; 3(1): 1015, 1-2.

6- E Balamurugan, Aggarwal M, Lamba A, Dang N, Tripathi M . Perceived trigger factors of seizures in persons with epilepsy, Seizure, Elsevier Ltd., 2013; 743-744.

7- Josefina Ricardo-Garcell et al. at . Clinical Study Epileptic Encephalopathy in Children with Risk Factors for Brain Damage, Epilepsy Research and Treatment, 2012;7.

8- Khan H. Consanguinity, family history, and risk of epilepsy: A case control study. Gulf Medical Journal. 2012;1(1):32-34.

9- Lewis SL, Dirken SR, Heitkemper MM. MEDICAL-SURGICAL NURSING Assessment and Management of Clinical Problems, $9^{\text {th }}$ ed., 2014; 1420-1421.

10- Mehndiratta MM, Paul B, Mehndiratta P. Arranged marriage, consanguinity and epilepsy. Neurol Asia. 2007; 12:15-7.

11- Novakova B, Harris PR, Ponnusamy A, Reuber M. The role of stress as a trigger for epileptic seizures: A narrative review of evidence from human and animal studies, Epilepsia, 2013; 54(11):1866-1868.

12- Wang H, Ning X, Luo J, Chen C, Lu X . Influential factors of epilepsy following aneurismal subarachnoid hemorrhage, Int J Clin Exp Med 2016;9(3):6795-6800.

13- Satishchandra P, Gururaj D, Mohammed D, Senanayake N, Sllpaklt O. Global campaign against: epilepsy out of shadows. Geneva: World Health Organization Press; 2005. 